\title{
Analysis of the Thermal Stress for Combined Electrode of Soldered Crystalline Silicon Solar Cells under Temperature Field
}

\author{
He Wang, ${ }^{1}$ Ao Wang, ${ }^{1}$ Hong Yang, ${ }^{1}$ and Dengyuan Song ${ }^{2}$ \\ ${ }^{1}$ School of Science, Xian Jiaotong University, Xian 710049, China \\ ${ }^{2}$ Yingli Group Co., Ltd., Baoding 071051, China \\ Correspondence should be addressed to Hong Yang; hongy126@126.com
}

Received 2 April 2016; Revised 21 August 2016; Accepted 30 August 2016

Academic Editor: Simona Binetti

Copyright (C) 2016 He Wang et al. This is an open access article distributed under the Creative Commons Attribution License, which permits unrestricted use, distribution, and reproduction in any medium, provided the original work is properly cited.

Based on the theory of material mechanics and thermal stress analysis, the stress distribution of combined electrode for crystalline silicon solar module was studied for the first time. The shear stress and normal stress distribution of soldered structure for crystalline silicon solar cells under the thermal field were discussed. And the results show that the stress distribution is not simply linear relationship as some results found. But there is a stress concentration at the edge, which was considered as the true reason that caused microcracks at the edge of soldered solar cells. The conclusions we got in this paper provide a theoretical basis for deceasing the breakage rates of soldered crystalline silicon solar cells and improving the reliability of crystalline silicon solar modules.

\section{Introduction}

Crystalline silicon solar cells have become the main force of the photovoltaic industry. Crystalline silicon solar module is the critical component of photovoltaic (PV) generation system. Effective controlling of power degradation and increasing the conversion efficiency have the same importance for the investment income and reliability of PV power plant [1-3]. Manufacturers usually guarantee that the lifetime of the solar cell module is expected to be 25 years with $20 \%$ reduction in its power output over this period. Installed and operated in hot and humid climate, the PV modules' typical operating temperature will change in the range $-30 \sim+100^{\circ} \mathrm{C}$. In the process of crystalline silicon solar modules production, the cells of PV modules are electrically connected in series by interlacing tin-coated copper ribbon. Due to the large difference of the coefficient of thermal expansion (CTE) between metal and silicon, thermal stress of such combined electrode will appear and accumulate in the metallization interconnection system when the PV module is suffering from a temperature cycle. The cyclic thermal stress will cause microcracks and voids, which will increase the contact resistance of the electrode and reduce PV modules' lifetime. Although many researches on module reliability have been done [4-7], there was no quantitative research for the thermal stress distribution of combined electrode inside the crystalline silicon solar module.

In this paper, a model of the thermal stress distribution of combined electrode for crystalline silicon solar module is established for the first time. The shear stress and normal stress distribution of soldered structure for crystalline silicon solar cell under the thermal field were discussed. And the results show that the stress distribution is not simply linear relationship as some results found [8]. But there is a stress concentration at the edge, which was considered as the true reason that caused microcracks at the edge of the soldered solar cell.

\section{Structure Model of Combined Electrode for Crystalline Silicon Solar Cells}

2.1. Theoretical Model. When the PV module is working outdoors and suffering from a temperature cycle, thermal 


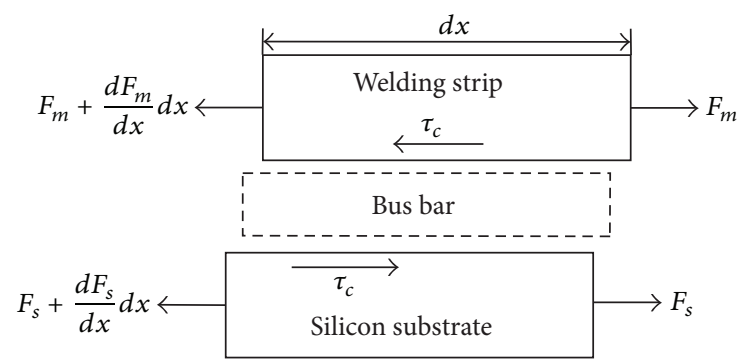

FIgURE 1: Mechanical analysis of the metallization interconnection system.

stress will be caused in different materials which have different coefficients of thermal expansion (CTE). Because of the adhesion and restriction between each structure material, a kind of stress cycle will appear in the interface and gradually lead to various reliability problems like crack, low power, or even failure [9].

As we know, glass layer is the main binder phase at Ag paste/Si contact interface, and the peeling off of cell electrodes always occurred in Ag paste layer. The coefficients of thermal expansion of metal materials are quite different from $\mathrm{Si}$ substrate, while the glass frit is between metal and Si. As shown in Figure 1, a simplified structure model with only three layers was established (Cu ribbon, $\mathrm{Ag}$ paste layer, and $\mathrm{Si}$ substrate). The assumption that each layer satisfies the homogeneous, isotropic, and linear conditions is made to simplify the model.

The thickness, width, and Young's modulus of each layer are $t_{m}, b_{m}$, and $E_{m}$ for ribbon, $t_{s}, b_{s}$, and $E_{s}$ for Si substrate layer, and $t_{c}, b_{c}$, and $E_{c}$ for thin glass layer, respectively. $L$ is the bond length. Considering the element shown in Figure 1, the equations of equilibrium for metal layer and Si substrate layer can be written as

$$
\begin{aligned}
& \frac{d F_{m}}{d x}+\tau_{c}=0, \\
& \frac{d F_{s}}{d x}-\tau_{c}=0 .
\end{aligned}
$$

$F_{m}$ and $F_{s}$ represent the forces caused by thermal stresses for metal layer and Si substrate layer. $\tau_{c}$ is shear stress in the middle layer.

\subsection{Thermal Stress Model of Combined Electrode for Crys-} talline Silicon Solar Cells. As shown in Figure 2, this paper takes the expansive behavior of solar cell under a high temperature as an example to analyze shear stress distribution. Figure 3 shows the structure deformation of an element in the location $x$. As the thickness of the middle thin glass layer is too thin, the shear stress in the glass layer can be considered as the same value $\tau_{c}$ along thickness, and the shear stress in metal layer and Si substrate layer changes linearly along thickness.
The shear stresses in the middle layer, metal layer, and $\mathrm{Si}$ substrate layer can be written as follows:

$$
\begin{aligned}
& \tau_{c}=\gamma_{c} G_{c}=\frac{\Delta x}{\Delta y} G_{c}=\frac{u_{c m}(x)-u_{c s}(x)}{t_{c}} \cdot G_{c}, \\
& \tau_{m}=\tau_{c}-\frac{\tau_{c}-\tau_{m}^{\prime}}{t_{m}} y, \\
& \tau_{s}=\tau_{c}+\frac{\tau_{c}-\tau_{s}^{\prime}}{t_{s}} y .
\end{aligned}
$$

$\tau_{c}, \tau_{m}$, and $\tau_{s}$ are the shear stresses in the middle layer, metal layer, and Si substrate layer, respectively. $\tau_{m}^{\prime}$ and $\tau_{s}^{\prime}$ are the shear stresses of the upper surface and lower surface. $u_{c m}(x)$ and $u_{c s}(x)$ are the coordinates of the two interfaces of the element in the location $x . u_{m}^{\prime}$ and $u_{s}^{\prime}$ are the coordinates of the upper surface and lower surface. $G$ and $\gamma$ are the shear modulus and shear strain, respectively.

According to the stress-strain relationship, the coordinate functions in metal layer and Si substrate layer can be expressed as

$$
\begin{aligned}
U_{m}(x, y) & =u_{c m}(x)+\int_{0}^{y} \gamma_{m}(y) d y=\int_{0}^{y} \frac{\tau_{m}(y)}{G_{m}} d y \\
& =u_{c m}+\frac{\tau_{c}}{G_{m}} y-\frac{\tau_{c}-\tau_{m}^{\prime}}{2 t_{m} G_{m}} y^{2}+C_{1}, \\
U_{s}(x, y) & =u_{c s}(x)+\int_{0}^{y} \gamma_{s}(y) d y=\int_{0}^{y} \frac{\tau_{s}(y)}{G_{s}} d y \\
& =u_{c s}+\frac{\tau_{c}}{G_{s}} y+\frac{\tau_{c}-\tau_{s}^{\prime}}{2 t_{s} G_{s}} y^{2}+C_{2} .
\end{aligned}
$$

The displacement functions $w(x, y)$ can be expressed as follows:

$$
w(x, y)=U(x, y)-x .
$$

Substituting (4) into (5), the displacement functions in metal layer and Si substrate layer can be expressed as differential equations:

$$
\begin{aligned}
& \frac{d w_{m}}{d x}=\frac{d u_{c m}}{d x}-1+\frac{y}{G_{m}} \frac{d \tau_{c}}{d x}-\frac{y^{2}}{2 t_{m} G_{m}} \frac{d \tau_{c}-d \tau_{m}^{\prime}}{d x}, \\
& \frac{d w_{s}}{d x}=\frac{d u_{c s}}{d x}-1+\frac{y}{G_{s}} \frac{d \tau_{c}}{d x}+\frac{y^{2}}{2 t_{s} G_{s}} \frac{d \tau_{c}-d \tau_{s}^{\prime}}{d x} .
\end{aligned}
$$

The normal stresses of element $d x$ for the metal layer and $\mathrm{Si}$ substrate layer under temperature field are expressed as

$$
\begin{gathered}
\sigma_{m}=E_{m} \frac{\alpha_{m} \Delta T d x-d w_{m}}{d x}=E_{m}\left(\alpha_{m} \Delta T-\frac{d w_{m}}{d x}\right), \\
\sigma_{s}=E_{s} \frac{\alpha_{s} \Delta T d x-d w_{s}}{d x}=E_{s}\left(\alpha_{s} \Delta T-\frac{d w_{s}}{d x}\right),
\end{gathered}
$$

in which $\alpha$ is the coefficient of thermal expansion (CTE). 


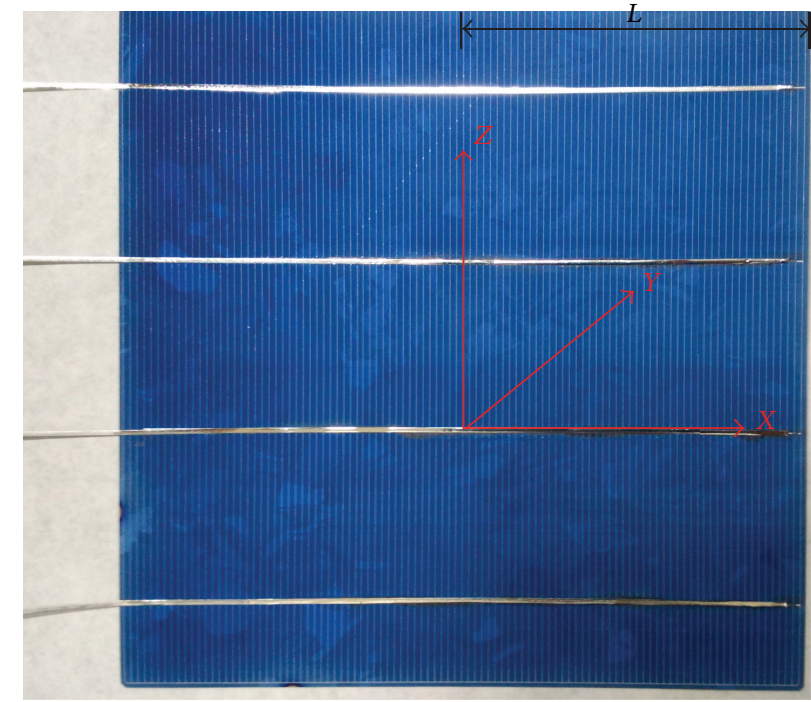

(a)

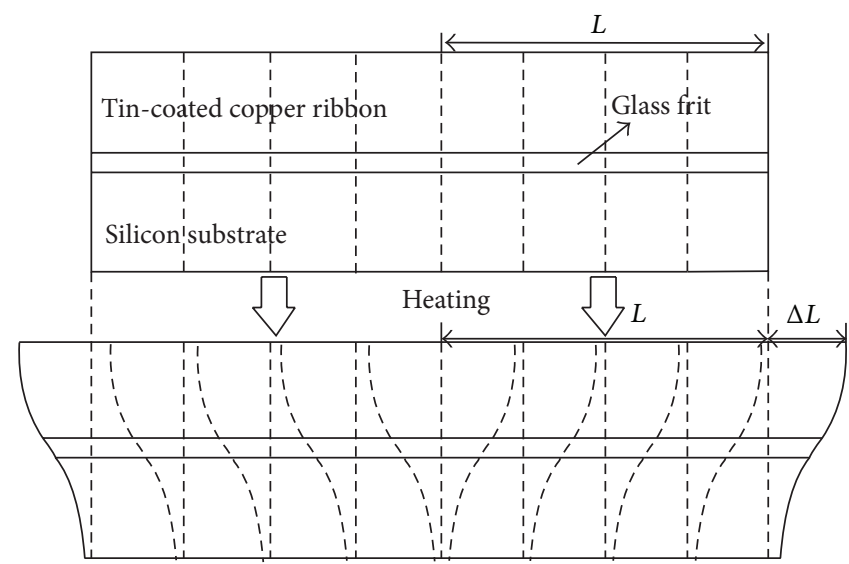

(b)

Figure 2: Simplification of cell structure. (a) Coordinate system with the origin at the center of the metallization. (b) Thermal expansion of the simplified structure.

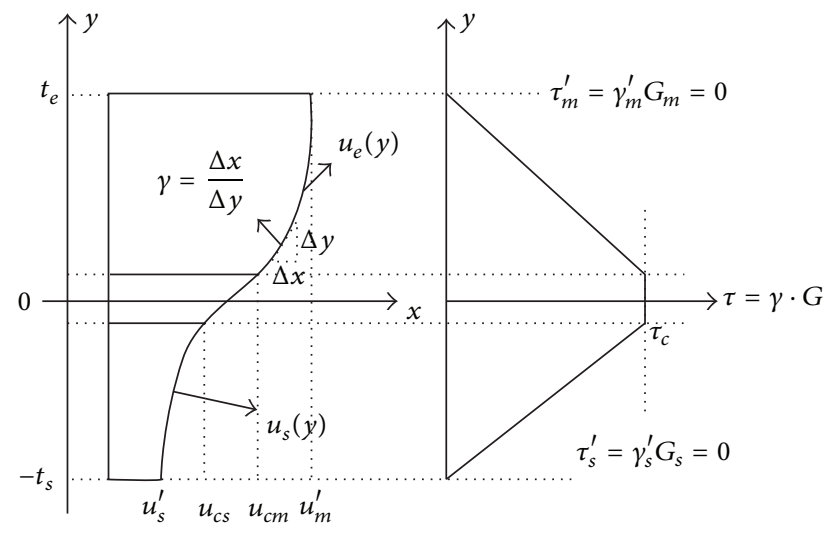

FIGURE 3: The shear stress and strain analysis of the simplified structure.

Compared to the thickness of the metal layer and Si layer, the middle layer is so thin that it can be reasonably ignored. The forces in metal layer and Si layer can be expressed as

$$
\begin{aligned}
F_{m}= & \int_{0}^{t_{m}} \sigma_{m} d y \\
= & E_{m} \alpha_{m} \Delta T \cdot t_{m} \\
& -E_{m}\left(\frac{d u_{c m}}{d x} t_{m}-t_{m}+\frac{t_{m}^{2}}{3 G_{m}} \frac{d \tau_{c}}{d x}-\frac{t_{m}^{2}}{6 G_{m}} \frac{d \tau_{m}^{\prime}}{d x}\right), \\
F_{s}= & \int_{0}^{-t_{s}} \sigma_{s} d y \\
= & -E_{s} \alpha_{s} \Delta T \cdot t_{s} \\
& +E_{s}\left(\frac{d u_{c s}}{d x} t_{s}-t_{s}-\frac{t_{s}^{2}}{3 G_{s}} \frac{d \tau_{c}}{d x}-\frac{t_{s}^{2}}{6 G_{s}} \frac{d \tau_{s}^{\prime}}{d x}\right) .
\end{aligned}
$$

They can also be written in the form of differential equation. Substituting (1) gives

$$
\begin{aligned}
& \frac{d^{2} u_{c m}}{d x^{2}}=\frac{\tau_{c}}{E_{m} t_{m}}-\frac{t_{m}}{3 G_{m}} \frac{d^{2} \tau_{c}}{d x^{2}}+\frac{t_{m}}{6 G_{m}} \frac{d^{2} \tau_{m}^{\prime}}{d x^{2}}, \\
& \frac{d^{2} u_{c s}}{d x^{2}}=\frac{\tau_{c}}{E_{s} t_{s}}+\frac{t_{s}}{3 G_{s}} \frac{d^{2} \tau_{c}}{d x^{2}}+\frac{t_{s}}{6 G_{s}} \frac{d^{2} \tau_{s}^{\prime}}{d x^{2}} .
\end{aligned}
$$

Equation (2) can be written in the form of the following differential equation:

$$
\frac{d^{2} \tau_{c}}{d x^{2}}=\frac{G_{c}}{t_{c}}\left(\frac{d^{2} u_{c m}}{d x^{2}}-\frac{d^{2} u_{c s}}{d x^{2}}\right) .
$$

Substituting (9) into (10) gives

$$
\frac{d \tau_{c}^{2}}{d x^{2}}-\beta^{2} \tau_{c}+C=0,
$$

where

$$
\begin{aligned}
& \beta=\left[\frac{1 / E_{m} t_{m}-1 / E_{s} t_{s}}{t_{s} / 3 G_{s}+t_{m} / 3 G_{m}+t_{c} / G_{c}}\right]^{1 / 2} ; \\
& C=\frac{t_{s}}{6 G_{s}} \frac{d \tau_{s}^{\prime}}{d x}-\frac{t_{m}}{6 G_{m}} \frac{d \tau_{m}^{\prime}}{d x} .
\end{aligned}
$$

As shown in Figure 3, the shear stresses of the upper surface and lower surface were very small and as well assumed to be 0 . That is to say, coefficient $C$ is 0 . Hence,

$$
\frac{d \tau_{c}^{2}}{d x^{2}}-\beta^{2} \tau_{c}=0
$$

By solving differential equation (13), we can get the shear stress of the middle layer in the following form:

$$
\tau_{c}=A \sinh (\beta x)+B \cosh (\beta x) .
$$


TABLE 1: Structural parameters of different material layers.

\begin{tabular}{|c|c|c|c|c|c|}
\hline Parameters & $E / \mathrm{Pa}$ & $\mathrm{G} / \mathrm{Pa}$ & $\alpha /{ }^{\circ} \mathrm{C}^{-1}$ & $t / \mathrm{m}$ & $L_{0} / \mathrm{m}$ \\
\hline $\mathrm{Cu}$ ribbon layer & $110 e 9$ & $30 e 9$ & $16.9 e-6$ & $210 e-6$ & \\
\hline Middle layer & $55 e 9$ & $1.96 e 9$ & $3.3 e-6$ & $3 e-6$ & $78 e-3$ \\
\hline Si substrate layer & $130 e 9$ & $58 e 9$ & $2.6 e-6$ & $180 e-6$ & \\
\hline
\end{tabular}

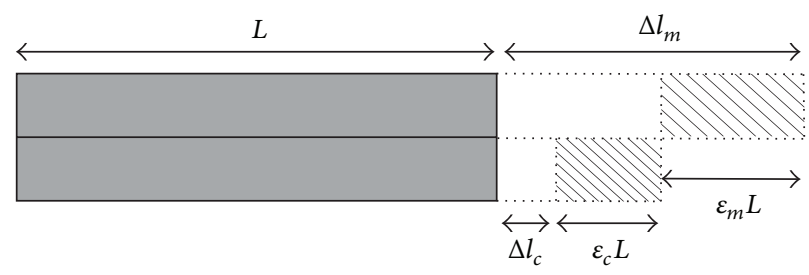

Figure 4: The normal stress and strain analysis.

The unknown constants $A$ and $B$ can be obtained by substituting the boundary conditions.

2.3. Boundary Conditions. Figure 4 gives out the analysis of the normal stress and strain. According to the thermal stress caused by expansion and contraction of materials under temperature $\Delta T$, the shear stress of location $L(x=L)$ can be calculated.

In the interface of metal layer and middle layer, two thin layers are analyzed. An assumption that the two thin layers are a rigid body and have the same cross section $(S)$ is made to simplify the problem. After the expansion behavior, the final length of this interface layer is $l_{c m}$.

The final length of this interface can be expressed as

$$
\begin{aligned}
l_{c m} & =L+\Delta l_{m}+\varepsilon_{m} L=L+\alpha_{m} \Delta T L+\varepsilon_{m} L \\
& =L+\alpha_{c} \Delta T L+\varepsilon_{c} L .
\end{aligned}
$$

For the two thin layers,

$$
\sigma_{m} S=-\sigma_{c} S
$$

According to the normal stress definition, there are

$$
\begin{gathered}
\sigma_{m}=-\sigma_{c}=-k_{1} \alpha_{m} E_{m} \Delta T, \\
l_{c m}=L+\alpha_{m} \Delta T L\left(1-k_{1}\right) .
\end{gathered}
$$

Similarly, by analyzing the interface of the middle layer and Si substrate layer, we got

$$
\sigma_{c}^{\prime}=-\sigma_{s}=-k_{2} \alpha_{c} E_{c} \Delta T
$$

in which

$$
\begin{aligned}
& k_{1}=\frac{1-\alpha_{c} / \alpha_{m}}{1+E_{m} / E_{c}} \\
& k_{2}=\frac{1-\alpha_{s} / \alpha_{c}}{1+E_{c} / E_{s}} .
\end{aligned}
$$

The final length of this interface can be expressed as

$$
l_{c s}=L+\alpha_{c} \Delta T L\left(1-k_{2}\right) .
$$

Therefore,

$$
\begin{aligned}
\tau_{c} & =\gamma_{c} G_{c}=\frac{l_{c m}-l_{c s}}{t_{c}} \cdot G_{c} \\
& =\frac{\alpha_{m} \Delta T L\left(1-k_{1}\right)-\alpha_{c} \Delta T L\left(1-k_{2}\right)}{t_{c}} \cdot G_{c} .
\end{aligned}
$$

With the boundary conditions $x=0, \tau_{c}=0$,

$$
\begin{aligned}
x & =L, \\
\tau_{c} & =\frac{\alpha_{m} \Delta T L\left(1-k_{1}\right)-\alpha_{c} \Delta T L\left(1-k_{2}\right)}{t_{c}} \cdot G_{c} .
\end{aligned}
$$

The unknown constants in (14) can be obtained by substituting the boundary conditions

$$
\begin{aligned}
& B=0 \\
& A=\frac{1}{\sinh (\beta L)} * k \alpha_{1} E_{1} T
\end{aligned}
$$

\section{Solution and Analysis}

The following results can be obtained by substituting the values of $A$ and $B$ into (14):

$$
\begin{aligned}
\tau_{c}= & \frac{\sinh (\beta x)}{\sinh (\beta L)} \cdot \frac{\alpha_{m} \Delta T L\left(1-k_{1}\right)-\alpha_{c} \Delta T L\left(1-k_{2}\right)}{t_{c}} \\
& \cdot G_{c} .
\end{aligned}
$$

Substituting the material parameters (shown in Table 1) into (25), curves of the shear stress in the middle layer 


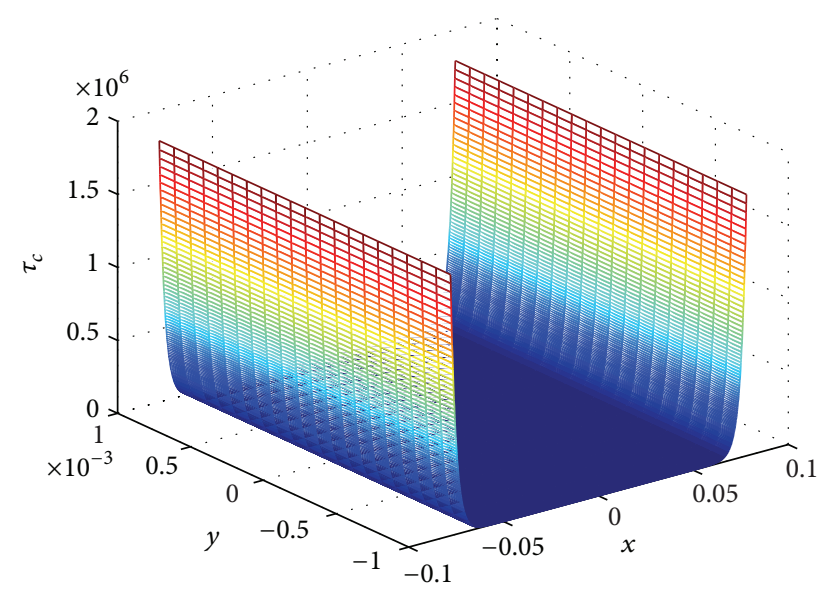

Figure 5: The shear stress distribution of the middle layer.

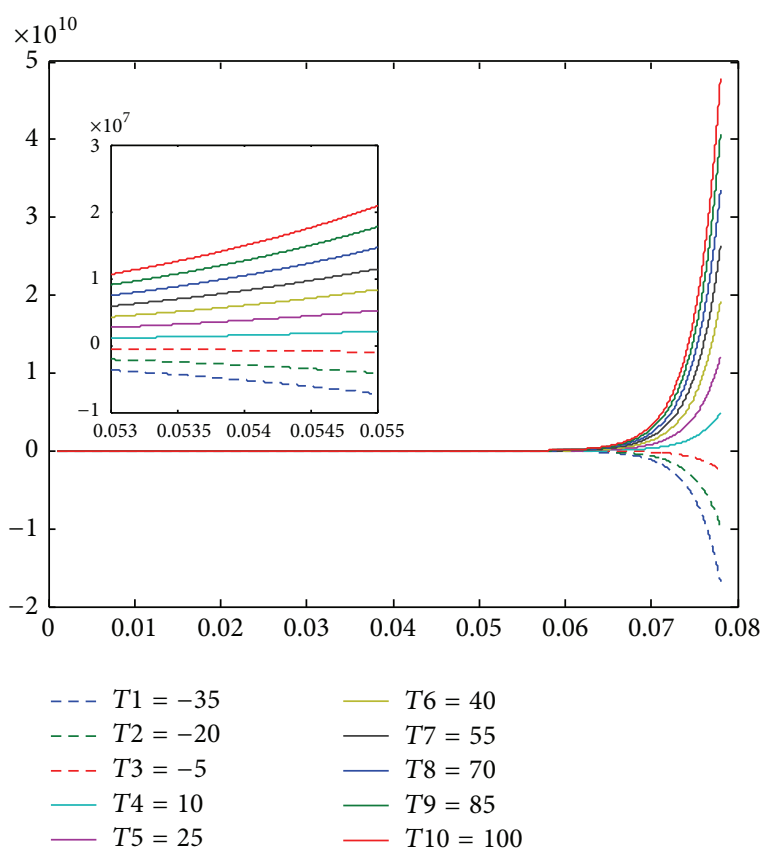

FIGURE 6: The shear stress distribution of the middle layer under temperature field from $-35^{\circ} \mathrm{C}$ to $100^{\circ} \mathrm{C}$.

were obtained by MATLAB. Figure 5 shows the shear stress distribution in the middle layer when the temperature is $55^{\circ} \mathrm{C}$. Figure 6 shows the shear stress in the middle layer under different temperature fields $\left(-35^{\circ} \mathrm{C},-20^{\circ} \mathrm{C},-5^{\circ} \mathrm{C}, 10^{\circ} \mathrm{C}, 25^{\circ} \mathrm{C}\right.$, $40^{\circ} \mathrm{C}, 55^{\circ} \mathrm{C}, 70^{\circ} \mathrm{C}, 85^{\circ} \mathrm{C}$, and $100^{\circ} \mathrm{C}$ ).

The final coordinates of the middle adhesive layer in $x$ can be obtained by (18) and (21) after the thermal stability:

$$
\begin{aligned}
& u_{c m}(x)=x+\left(1-k_{1}\right) \alpha_{m} \Delta T x=x+\left(1+k_{1}\right) \alpha_{c} \Delta T x \\
& u_{c s}(x)=x+\left(1-k_{2}\right) \alpha_{c} \Delta T x=x+\left(1+k_{2}\right) \alpha_{s} \Delta T x
\end{aligned}
$$

Taking the derivatives of (26) with respect to $x$ and substituting them into (6), the following relationships were obtained:

$$
\begin{aligned}
\sigma_{m}= & E_{m} k_{1} \alpha_{m} \Delta T-E_{m}\left(\frac{y}{G_{m}}-\frac{y^{2}}{2 t_{m} G_{m}}\right) \\
& \cdot \frac{\beta \cosh (\beta x)}{\sinh (\beta L)} \\
& \cdot \frac{\alpha_{m} \Delta T L\left(1-k_{1}\right)-\alpha_{c} \Delta T L\left(1-k_{2}\right)}{t_{c}} \cdot G_{c} \\
\sigma_{s}=- & E_{s} k_{2} \alpha_{s} \Delta T-E_{s}\left(\frac{y}{G_{s}}+\frac{y^{2}}{2 t_{s} G_{s}}\right) \cdot \frac{\beta \cosh (\beta x)}{\sinh (\beta L)} \\
& \cdot \frac{\alpha_{m} \Delta T L\left(1-k_{1}\right)-\alpha_{c} \Delta T L\left(1-k_{2}\right)}{t_{c}} \cdot G_{c} .
\end{aligned}
$$

By (27), when $x$ is a fixed value, the relationship of normal stress and $y$ is a quadratic function. When the value of $y$ is 0.03 , the distribution of upper and lower normal stress can be simulated by MATLAB. The result of simulation is shown in Figure 7.

\section{Experimental Verification for the Thermal Stress Model of Combined Electrode for Soldered Crystalline Silicon Solar Cells}

According to the above analysis, the stress of the soldered solar cells' side increases with increasing solder temperature, so microcracks induced by high stress begin from the side of the soldered solar cells. Figure 8 gives out the electroluminescence images of crystalline silicon solar module with microcracks at the edge of the soldered solar cell induced by thermal stress.

From Figure 8, the microcracks always emerge on the side of the combined electrode for crystalline silicon solar cells. This proved the validity of the thermal stress model for soldered crystalline silicon solar cells. From the results, the way to decrease the breakage rates of soldered crystalline silicon solar cells is to reduce the thermal stress of combined electrode during the production of crystalline silicon solar modules.

\section{Conclusions}

In this paper, the stress distribution of combined electrode for crystalline silicon solar module was studied for the first time. The shear stress and normal stress distribution of soldered crystalline silicon solar cell under the thermal field were discussed. Studies have shown that the value of shear stress at the midpoint is the smallest and the shear stress along the direction of welding strip increases by function of cosh. The concentrated stress of edges leads to microcracks of the soldered solar cells. The results laid a theoretical basis for reducing the breakage rates of soldered crystalline silicon solar cells and improving the reliability of crystalline silicon solar modules during the production of solar modules. 


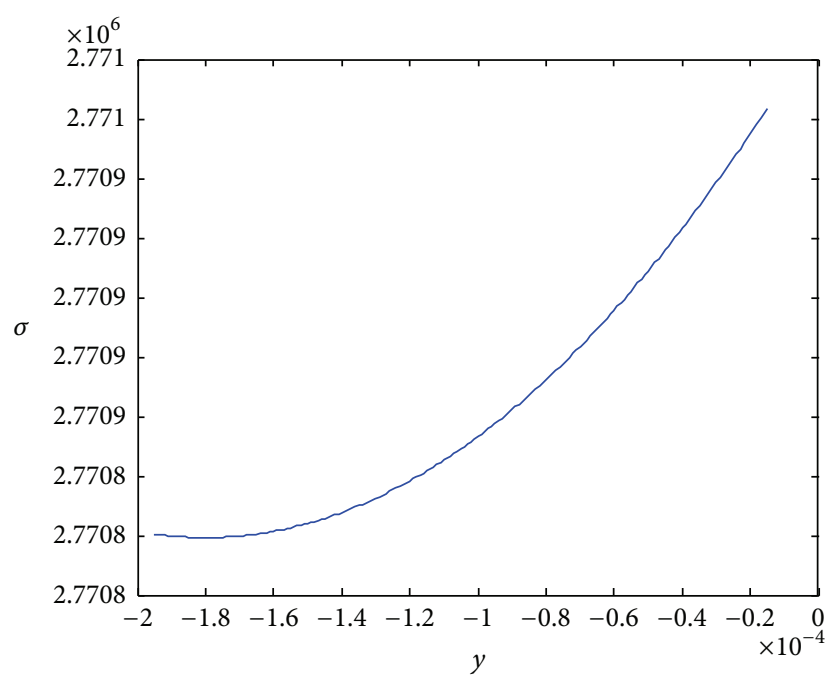

(a)

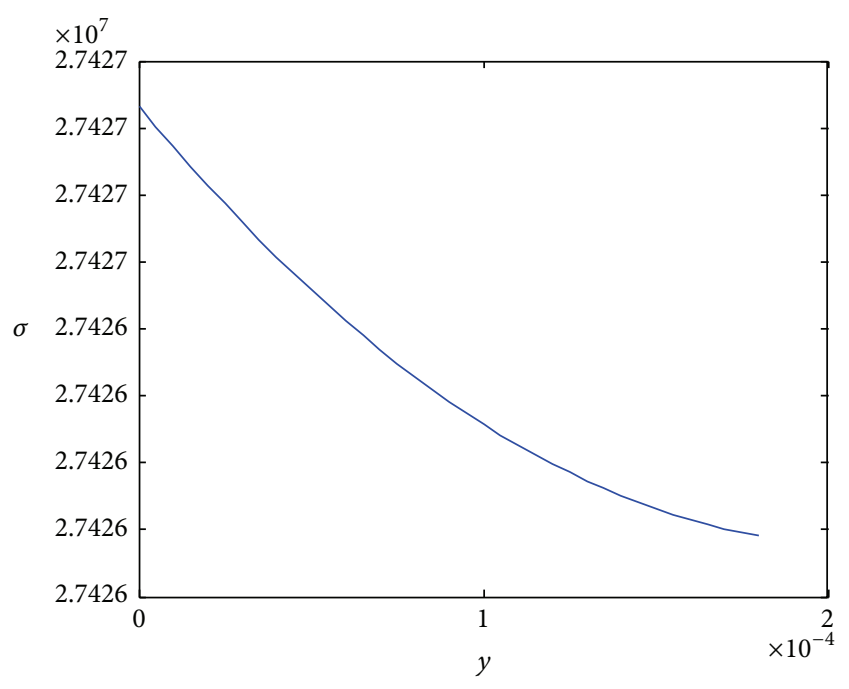

(b)

FIgURE 7: The normal stress distribution in Si substrate (a) and ribbon (b).
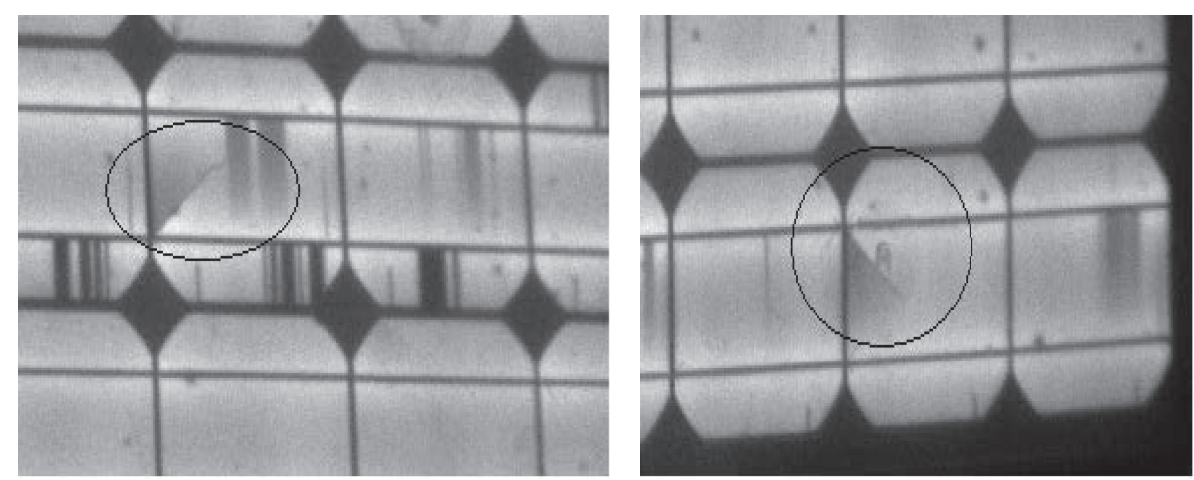

FIGURE 8: The electroluminescence images of solar modules with microcracks at the edge of soldered solar cell induced by thermal stress.

\section{Competing Interests}

The authors declare that they have no competing interests.

\section{Acknowledgments}

The authors would like to acknowledge the support of the National High Technology Research and Development Program of China (Grant no. 2015AA050301). This study was also supported by the Natural Science Foundation of China (Grants nos. 61274050 and 61376067).

\section{References}

[1] H. Yang, H. Wang, D. Cao, D. Sun, and X. Ju, "Analysis of power loss for crystalline silicon solar module during the course of encapsulation," International Journal of Photoenergy, vol. 2015, Article ID 251615, 5 pages, 2015.

[2] M. T. Zarmai, N. N. Ekere, C. F. Oduoza, and E. H. Amalu, "A review of interconnection technologies for improved crystalline silicon solar cell photovoltaic module assembly," Applied Energy, vol. 154, pp. 173-182, 2015.
[3] A. Metz, D. Adler, S. Bagus et al., "Industrial high performance crystalline silicon solar cells and modules based on rear surface passivation technology," Solar Energy Materials \& Solar Cells, vol. 120, pp. 417-425, 2014.

[4] A. Limmanee, N. Udomdachanut, S. Songtrai et al., "Field performance and degradation rates of different types of photovoltaic modules: a case study in Thailand," Renewable Energy, vol. 89, pp. 12-17, 2016.

[5] J.-S. Jeong, N. Park, and C. Han, "Field failure mechanism study of solder interconnection for crystalline silicon photovoltaic module," Microelectronics Reliability, vol. 52, no. 9-10, pp. 23262330, 2012.

[6] H. Yang, H. Wang, C. Chen, D. Cao, and H. Yu, "Effect of binding force between silver paste and silicon on power degradation of crystalline silicon solar module," Microelectronics Reliability, vol. 54, no. 1, pp. 188-191, 2014.

[7] G. Cuddalorepatta, A. Dasgupta, S. Sealing, J. Moyer, T. Tolliver, and J. Loman, "Durability of Pb-free solder between copper interconnect and silicon in photovoltaic cells," Progress in Photovoltaics: Research and Applications, vol. 18, no. 3, pp. 168182, 2010.

[8] C.-M. Lai, C.-H. Su, and K.-M. Lin, "Analysis of the thermal stress and warpage induced by soldering in monocrystalline 
silicon cells," Applied Thermal Engineering, vol. 55, no. 1-2, pp. 7-16, 2013.

[9] D. C. Jordan and S. R. Kurtz, "Photovoltaic degradation ratesan analytical review," Progress in Photovoltaics: Research and Applications, vol. 21, no. 1, pp. 12-29, 2013. 

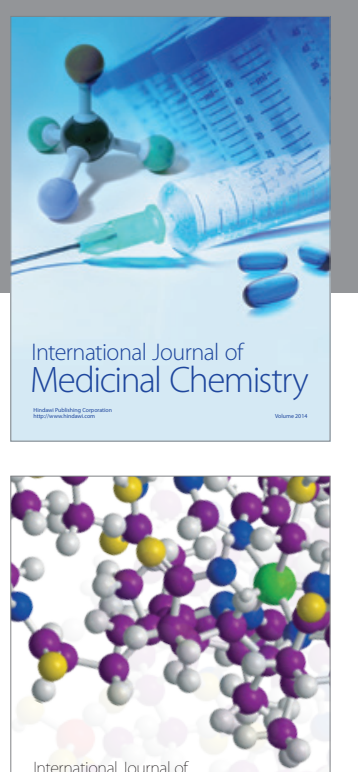

Carbohydrate Chemistry

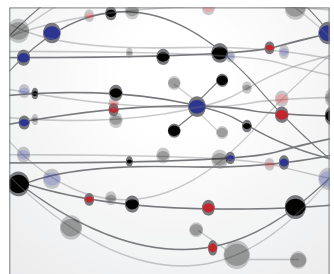

The Scientific World Journal
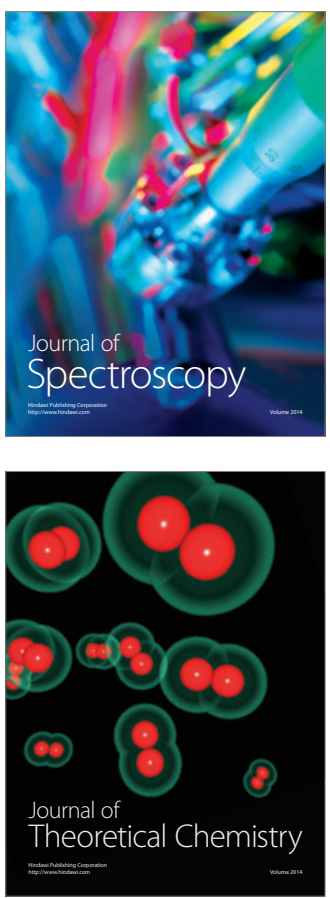
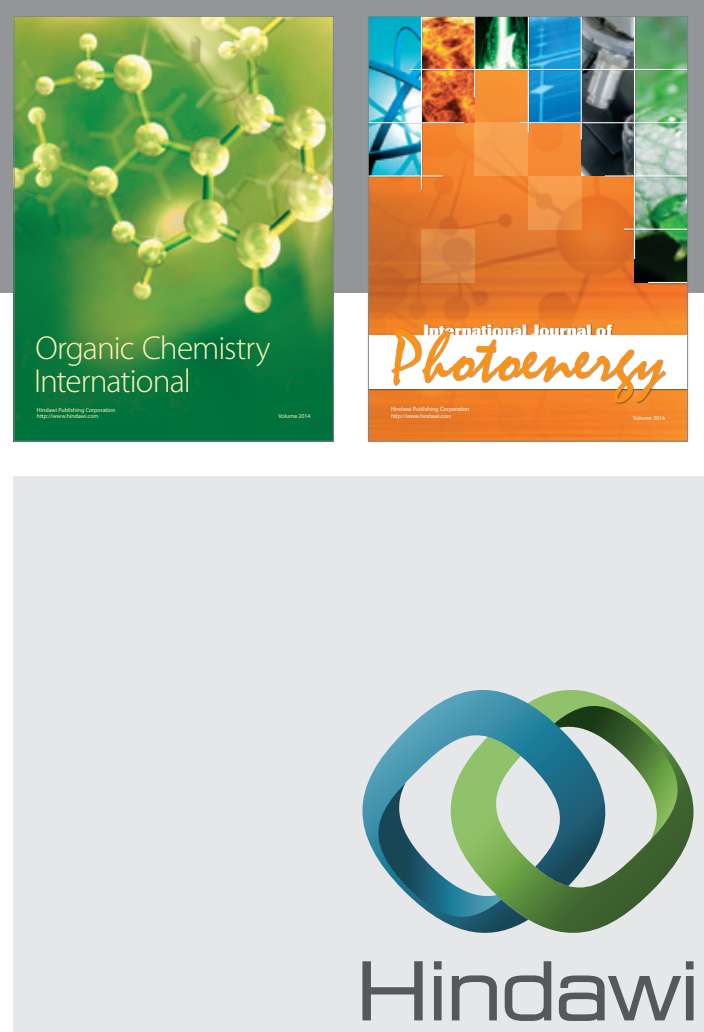

Submit your manuscripts at

http://www.hindawi.com

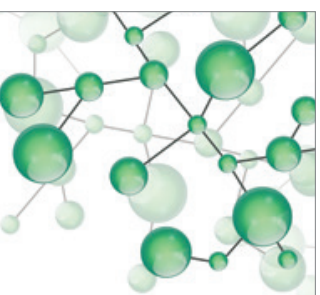

International Journal of

Inorganic Chemistry

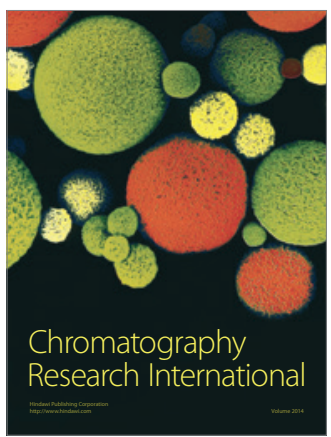

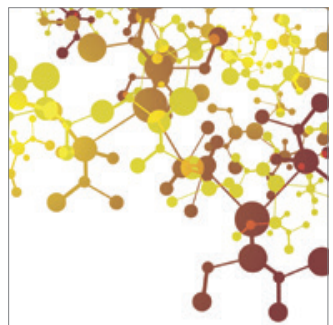

Applied Chemistry
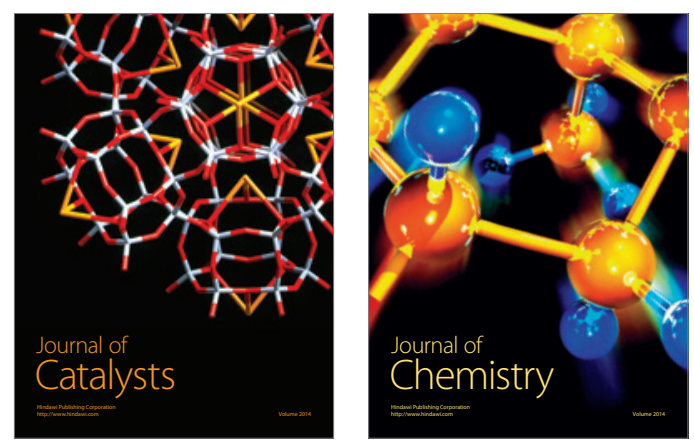
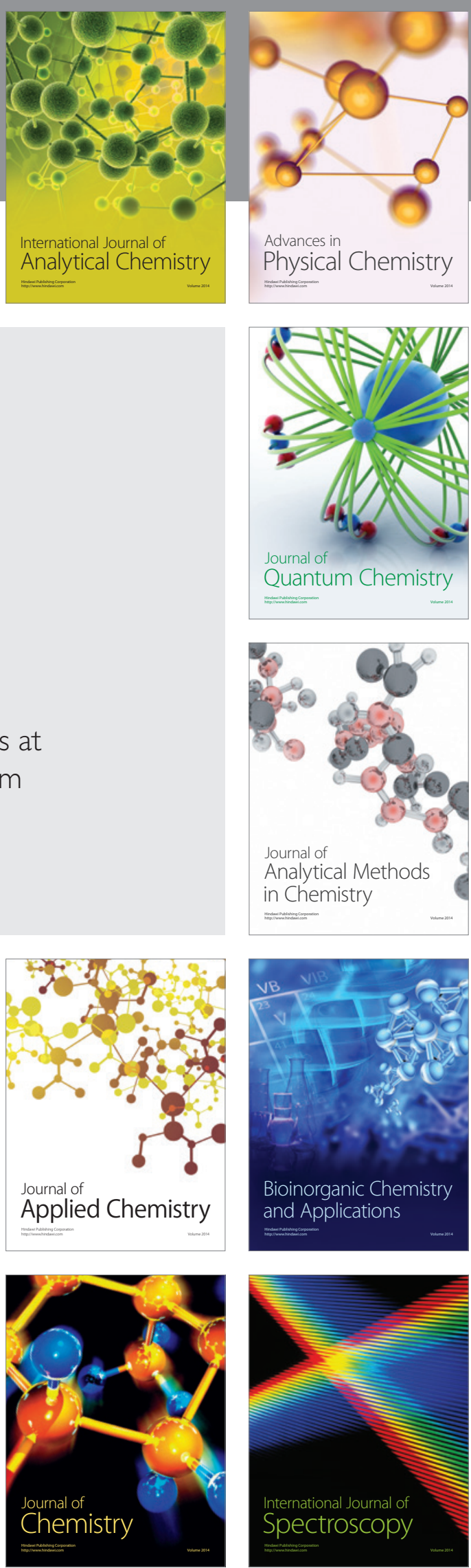